\title{
Awareness, Transience and Temporality: Design Opportunities from Rah Island
}

\author{
Pedro Ferreira ${ }^{1}$, Pedro Sanches ${ }^{2}$, and Alexandra Weilenmann ${ }^{3}$ \\ ${ }^{1}$ Kungliga Tekniska Högskolan, The School of Computer Science and Communication, \\ 10044 Stockholm, Sweden \\ ${ }^{2}$ Swedish Institute of Computer Science, Isafjordsgatan 22/Kistagången 16, Box 1263 \\ 16440 Kista, Sweden \\ ${ }^{3}$ University of Gothenburg \\ 10691 Göteborg, Sweden \\ pedro@mobilelifecentre.org, sanches@sics.se, \\ alexandra.weilenmann@gu.se
}

\begin{abstract}
This paper deals with the implications of the socialness of private communication. Drawing upon ethnographic observations of first time mobile phone users in Rah, an island in Vanuatu, we revisit the debate on how the mobile phone reconfigures private and personal communication. Our observations show how the advent of the mobile phone disrupts and challenges existing practices around how private communication is managed on the island. These observations are used to open up a design space where we explore the socialness of personal, private communication. Drawing on the analysis, we discuss three directions for future thinking of mobile interaction design: (1) designing for spatial awareness; (2) designing for transience and (3) designing with temporality. We expand on these to discuss the notion of digital patina, which we argue, is an exciting topic to explore for the design of personal, social communication.
\end{abstract}

Keywords: Privacy, personal communication, social communication, transience, temporality, translucence, awareness, design.

\section{Introduction}

Mobile telephony has opened up for different forms of socio-technical reconfigurations wherever it has sprung up. We have seen a variety of reports and publications that account for the ways old forms of socialization and power are challenged, opening up for radically new forms of engagement, which are still developing and taking different shapes. Studies from places as distant as Sweden [1, 2], the Philippines [3], Japan [4], Jamaica [5] or Israel [6] among others, despite providing us with rich and diverse pictures, also point to similar, emerging behaviors, some of which we will follow up on in this work. One such aspect that has been suggested early on was that mobile phones would allow for more private communication, since it was thought of as a personal device, rather than, for instance, a device going into people's homes or workplaces [7, 8]. 
In this paper, we wish to revisit this discussion, and in doing so we draw upon a set of observations from an ethnographic study conducted in Rah Island, Vanuatu, a nation in the South Pacific. Particularly, we observed how the mobile phone reconfigured private communication on the island, thereby disrupting and challenging existing practices for how people communicated. The observations from the field allow us to rethink the way that privacy is considered in relation to mobile phone use, and enable us to open up a design space dealing with the socialness of private communication. We use this argument as an inspiration to consider design implications on how to explore the socialness of this type of communication.

We will analyze two situations in which mobile communication was at odds with expectations on privacy: the persistent nature of digital data and the layering of different spaces in communication. Using three concepts from Social Translucence: visibility, awareness and accountability [9], as a lens, we argue for three design domains worth exploring in HCI: spatial awareness, temporality and transience. We conclude by introducing the concept of digital patina, as a possible consequence of the exploring the domains introduced, and an exciting one to unpack in HCI.

\section{On the Study and Approach}

The data used as a starting point for our discussion in this paper are part of a larger ethnographic study conducted in Rah Island, in Northern Vanuatu, in February 2010. The data was analyzed with the help of colleagues, through different sessions (or workshops) where we analyzed bits of data trying to map out what the main insights for HCI could come from this fieldwork. Other papers have been published on this fieldwork, focusing on aspects of bodily orientations around mobiles [10] and playfulness and mobiles [11]. The data and insights presented in this paper are however mostly undocumented in our previous publications. Before we move on, we will provide a framing for the study conducted, both in terms of the location, the source of the data gathered as well as our particular approach to dealing with ethnographic data in an interaction design context.

\subsection{Studying Mobile Phone Use on Rah Island}

Rah Island is a small island of around 189 inhabitants [12] in Northern Vanuatu, a Melanesian country in the South Pacific. A cellphone tower had just begun working in the area, the very same day the first author, who conducted the fieldwork, arrived in the island, The tower was placed in Motalava, a larger island almost adjacent to Rah, where one could walk across during low tide, as can be seen in Fig. 1. This meant that the almost three weeks the researchers spent in the island were the first weeks of GSM connectivity on these islands. Perhaps worth noticing is the fact that many mobile phones were already present in the Island, at this time, given that they were sold by the network operator months before, as part of a network launching promotional package. When the tower began operating, many phones were already present, awaiting connectivity. 


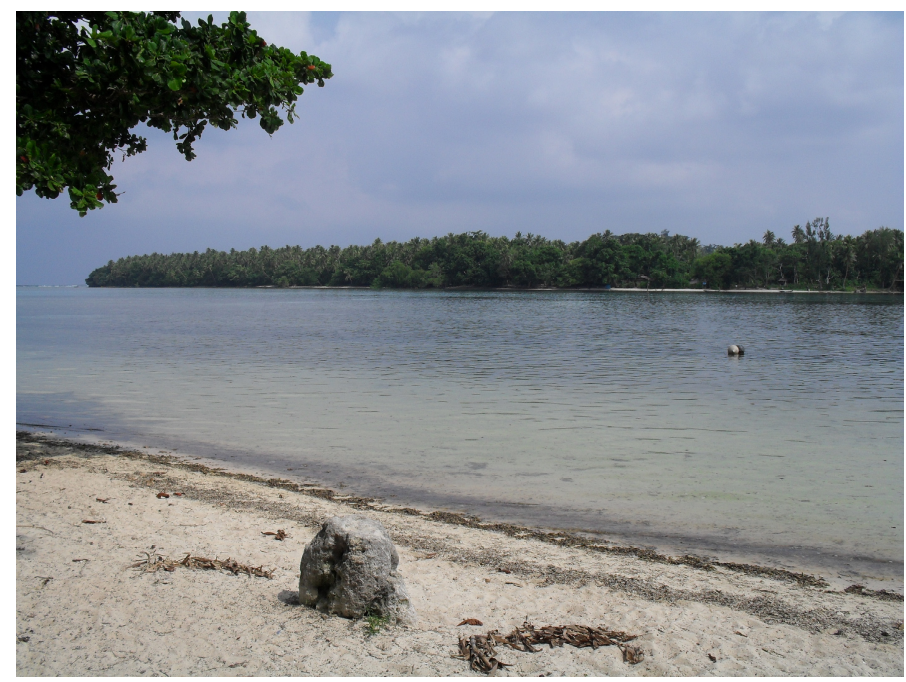

Fig. 1. Rah Island, as seen from the shore in Motalava

Rah and Motalava are two islands where, at the time of the study, there was no centralized means of electricity production and where people lived mainly of their own agricultural practice with only a small minority disposing of regular financial income [12]. The first author spent a total of around three weeks in the Island, during which he collected observation data, including around a couple of hours of video, almost two hundred photographs and around 30 pages of fieldnotes. He also conducted four semi-structured interviews, though there was some difficulty in attracting people's time and attention for long amounts of time. The quotes used in this paper are thus mostly from notes taken during informal conversations, often in groups of more than one person. Some of the data comes from different local meetings, usually held at the request of the local community, either for us to explain the purpose of our stay in Rah, or as a way for people to express different concerns and requests. These meetings were first held under the assumption, which we immediately corrected, that we were coming there on the behalf of the telecommunications company. This entailed that they were particularly keen on expressing concerns and requests.

In this work we focus on the potential contributions that this particular ethnographic fieldwork might bring to interaction design practice and research. The use of ethnography in HCI has been the object of much controversy [e.g 12, 13]. We take a particular stance, which is very much design-oriented rather than ethnographiccentric, concerned more with advancing the field of mobile interaction design, rather than theoretical advances in ethnography or advancing the knowledge of a particular cultural setting. Thus, we focus on particular bits of data, which inspired our design thinking and informed our discussion rather than presenting a comprehensive ethnographic account or "thick description" [15] of the culture and practices in Rah. We focus on drawing broader inspiration for design [14], in someway pursuing "ethnographically inspired design", instead of following a more "ethnographically informed design" approach in the strict sense, as if ethnographic work would serve as a sort of "requirements gathering". 
In fact, the informants that will appear in this work are not even seen here as the ultimate benefiters (or users) of any potential system, or specific design contributions. Rather, in this paper, the fieldwork is drawn upon in order to inspire thinking about design in HCI, by unpacking mundane aspects of mobile phone usage in relation to everyday privacy concerns and management of secrecy, expressed and illustrated by observations in Rah. It is more a matter of uncovering somewhat hidden or overlooked opportunities within design oriented HCI, which can add value to designing for a wide variety of settings, practices and systems. In making this connection, we have relied upon visibility, awareness and accountability, all key concepts within HCI and CSCW, as formulated by Erickson and Kellog in their social translucence [9] approach. This will be expanded upon in the next section.

\subsection{Social Translucence as a Design Approach: Visibility, Awareness and Accountability}

Social translucence [9] is a systems design approach developed over a decade ago, as a method to design collaborative systems for large groups [9]. Three concepts are introduced which we used to take our observations and move into a design reasoning process: visibility, awareness and accountability. Ericksson and Kellogg illustrate social translucence with a metaphor drawn from the physical word: a glass window on a door, as a way of mediating the social interaction between the outside and outside users of this same door. In the case described by the authors, the glass window comes as a solution to the problem of knowing whether someone is standing outside the door before one attempts to open it, potentially bumping the door against the other person. By having the glass window, they argue, one is able to see on the other side and thus be able avoid this inconvenient incident.

Visibility, the first of the concepts, refers to the socially significant information, which is now available to people on both sides of the door, that is, the person on the other side. That is a property of the glass window within the context in which it was installed. Visibility, the authors argue, allows for the emergence of awareness and accountability, which will be responsible for the upkeep of the social conventions.

The awareness that someone is on the other side of the door, helps avoid the inconvenient situation, as the authors put it: "we have been raised in a culture in which slamming doors into other people is not sanctioned" [9]. Thus, by knowing there is a person on the other side, one is made aware of a potential awkward incident, and so could be persuaded to avoid it.

This brings us to the third concept, that of accountability. Accountability means that each person is aware that the other is aware. Or, in the authors' words: "I know that you know that I know you're there and therefore I will be held accountable for my actions" [9]. So accountability refers to the fact that, regardless of whether each of the people involved in that situation (of coming face to that door and ultimately deicing to open it), are not only already aware, but they are aware of the other's awareness, and so deciding to open the door at that precise moment, and ignoring the others' presence, is not only breaking a social norm, but is doing so, knowing the other might hold them accountable. 
We found these principles useful for looking at situations regarding privacy and the violation of secrecy around mobile phones. Particularly, we were inspired by their questions: "What might it mean to have social translucence in a digital system? How might making social information more visible actually change the way digital systems are used? Why might this be a desirable thing?" These were the main questions, which drove our process of harnessing Social Translucence as a generative concept for HCI, when looking at situations which are not apparently, or strikingly social.

\section{Privacy, Secrecy and Mobile Communication}

Privacy is a long-standing concern within the field of human computer interaction. As argued in the introduction, we wish to draw particular attention to the implications of the social character of private communication. It has been argued, as the mobile phone was introduced in different settings, that it allowed for more private communication [e.g. 4, 7, 8]. In contrast to this body of work, more complex pictures have been documented, for instance when it comes to sharing of mobile phones. Of particular importance for our discussion here is the body of work, which challenges this strict notion of mobile phones as an individual technology [2] noted how young people had various ways of sharing their personal devices. By sharing information on their phones, by passing them around or reading aloud, these young people had found interactional strategies to integrate their phones into their social activities, in ways that challenge the personal nature of this device. This behavior was such an integrated part of their ways of using their phones that those sending messages oriented to the fact that others, than the owner of the phone to which the message was being sent, might potentially read that message. In a similar vein, there is a body of work describing text messaging among this younger age group as a form of gift giving [16], providing further evidence to the social character of the mobile phone. Other studies show how communication on the phone is not just a social situation involving the person you are communicating with, it is also a social situation in other ways. When we are talking on the phone we sometimes withdraw from the current situation, but it is important to recognize that also that action is a social action [17-19].

Obviously, these types of social and sharing behaviors around personal devices and information call for more different interactional mechanisms if one is worried about preserving a certain degree of privacy, or secrecy, in relation to one's data and communication. We will return to this point when discussing our material from the field.

Finally, it should be added that while privacy is a complex and loaded concept within HCI, we use the term here in its most commonsensical and mundane sense. "Privacy" and "secrecy" are used interchangeably referring to the same phenomenon. Along these lines we will also refer to terms such as "eavesdropping" in the commonly understood sense of the term, as defined by Black's Law Dictionary: "the act of secretly listening to the private conversation of others without their consent". We are not referring to advanced technological eavesdropping techniques or concepts also used in HCI or Computer Science. 


\section{Dealing with New Means of Private Communication on Rah}

At the time mobile connectivity was launched in Rah, there was already one landline post existing in Motalava, situated fairly close to the shore connecting to Rah. The landline had been in use for several years, allowing for phone communication to and from outside the island. The arrival of mobile phone connectivity was something that extended those possibilities by quite a bit. It was now possible to perform phone calls from within the islands as well as calls to and outside the islands from different locations. These possibilities, in particular of intra-island communication was seen with some wit some concern, such as Fajo who wondered: "who knows what the younger ones are conspiring? [...] It is a very worrying situation". So even if one could see many manifestations of joy over the arrival of mobile telephony, it was also not rare to hear these types of concerns. As in any society, these new technologies, and modes of sociality between people defied the current state of things and prompted both happiness as well as concern.

These concerns are supported by studies in other contexts, showing for instance, how mobiles have been used by teenagers to create private/secret arenas for communication outside of parental control [3,7]. This increase of secrecy, as a side effect from the introduction of mobile communications was not the whole story, as we will illustrate in the following examples. We will focus on two situations, which inspired us to explore this domain: the layering of the physical space, with the virtual space of mobile communication and the challenges presented by the persistent nature of digital information.

\subsection{Layering of Spaces}

As we arrived in Rah, we were conducted to a town meeting so that we could openly explain what our study was about, listen to people's concerns and suggestions, as well as answer several questions people had regarding mobile telephony, given its very recent introduction. The participation was very broad, and lasted for quite a long time. Once people were seemingly satisfied with our answers and justifications we headed back to our bungalows to sleep. At this moment, one of the locals came up to us, in a very secretive fashion and speaking in a very low tone, as if concerned someone could overhear us. This person expressed concerns over the lack of privacy he had experienced with mobile phones: "Before, with TVL [the landline infrastructure was also provided by TVL] you can talk, and no one hears [...] now, with the mobile phone, everyone can hear your conversation". After that he claimed he had given up his mobile phone and reverted to the landline phone as his only means of phone communication. This came to us a surprise at first, since we intuitively felt that the possibility of moving around in space with a personal device, apparently independent from fixed physical locations, would represent an increase in privacy. This was also the concern expressed to us by Fajo previously, as well as something documented in previous research [8] where the ability to move around with the phone in the physical space as well as the ability to conceal oneself are seen as increase in the potential of secrecy, rather than a threat to it. 
One can speculate that the usage of the landline, in terms of trust, has been one that has been negotiated for a longer time than that of the mobile phones. This may be one of the reasons that the landline presented itself as an intuitively better choice. Later, Jorege, one of our main informants, complemented this suspicion, by expressing similar concerns: "everyone can hear when talking on the mobile", Jorege complained. When we witnessed Jorege performing a phone call on the mobile, we began to understand what the problem was. As Jorege stood up to answer the phone, he walked back and forth along the seashore, repeating louder and louder "Hello! Hello?" He then hung up, failing to get a clear communication line, telling us that this was precisely the problem. The low strength of the network connectivity in certain parts of the island and at certain times had certain unintended consequences. This observation echoes studies in Western environments, showing how the mobile phone makes people behave differently in public places, sometimes in ways that provoke strong reactions (e.g. [20]).

First and foremost the network issues induced people into concentrating in areas of the island where the signal was stronger. Generally speaking this was by the water, facing Motalava, where the phone tower was installed. This resulted in large gatherings around those areas, of people making and receiving phone calls, as well as many just sitting around waiting for potential calls. This immediately made those areas populated with many different potential people overhearing conversations, possibly unintentionally. Secondly, and within that area and others, it got people moving back and forth while talking on their phones, seeking a better quality of communication, in those moments, presumably, the focus was not so much on where they were walking or who could be overhearing the conversation, but mainly on having a reliable and audible communication channel. Finally, it made people speak louder and louder on their mobiles and repeating the same sentences several times, in order to get their messages across. What was interesting, in any case was that, rather than simply allowing for a private, intimate sphere of communication, it resulted in a distancing from the physical situation, causing a loss of awareness of the surroundings, as well as one's own tone of voice and so on. Although it is also the case that the speaker is still attending to the local environment in certain ways, this can be seen as a form of "absent presence" [21],

This example from the field illustrates a situation in which the intersection of different spaces, such as the space where people are physically present and the space where there is network connectivity, intersecting to generate an awkwardness in regards to privacy, very different from the challenges presented by the landline, geographically fixed, phone. While we have discussed in previous work how this different layering of landscapes impacts the way bodies orient themselves in space [10], here we examine the implications for the intersection between private and public.

Drawing on social translucence, one can see how the visibility of others could be immediately present, yet, given this "absence presence", an extra effort is required to keep track of both the communication on the mobile and keeping a constant awareness of others in the surrounding. We will draw on this in the discussion later by extending the concept of visibility, not just to other people but the network itself, treating the network coverage as relevant social information for this particular interaction. 


\subsection{On the Persistent Nature of Digital Data}

Given the prevalence and enthusiasm around mobile telephony, it was clear that there were many desirable aspects to them in comparison to the landline. One such aspect, highlighted by Jorege, addressing the previous concerns around lack secrecy and intermittent communication, was the SMS. In fact the SMS had two advantages from Jorege's perspective. One was that, given the often-poor quality of the network signal, the SMS represented a single packaged communication unit that would go through completely or not, allowing for a potentially less ambiguous form of communication. The other advantage was that it assured Jorege that "no one listens to what I [Jorege] say", and thus allowing for a more private mode of communication.

As we will now illustrate, that was not the whole story when it came to SMS communication. To illustrate this issue we relate an encounter from the field, of a young couple, Lisa and Robert who, for about eight months, had been in a secret, and otherwise forbidden relationship with each other. We do not intend to unpack all the cultural complexities of the forbidden nature of their relationship, nor is it of added value for the purpose of this paper. Suffice is to say that, prior to the arrival of the mobile phone, as Lisa told us, communication and arrangement of meetings between the young couple was made possible by using close friends as couriers. Despite their cautionary measures, one night, Lisa's sneaking out from her parents' house to visit Robert did not pass unnoticed, and her relationship was exposed to the whole community. At that time, and in order to avoid further problems they assured their parents and the community that they would stop seeing each other.

When mobile phones arrived to the island, at the time of our visit to Rah, the romance was still active. The couple was taking additional measures now, to ensure secrecy, and they saw the mobile phone as an opportunity to do so. Without the need to engage others in their secrets, Lisa and Robert were now using SMS to communicate: "I text him every morning to wish him a good day", Lisa told us. Although they were now able to communicate directly with each other, without the need of frequent physical proximity, and despite no one else being involved in their secret anymore, the usage of SMS turned out to have flaws of its own. Perhaps underestimating her father's technological skills, she left her mobile in the house one day, and while she was away her father went through her phone's inbox, and found out that Lisa and Robert were still involved in a relationship.

Perhaps as a consequence of this episode, as well as other concerns, and despite the relative novelty of mobile communications, the concern over phones as facilitating this type of forbidden relationships were echoed throughout our interviews in Rah: "boys are meeting girls in secret", said Fajo, "[mobiles provide] easy access for boys to call girls", echoed Fali. Other situations around married couples were also reported: "mobiles have been causing problems inside the family [...] already five mobile phones went to the toilet for causing conjugal disturbances", concerns echoed by Fajo: "it is recent [the arrival of the mobile] but already causing disturbances [...] maybe someday will cause divorce [...] married people are calling other married people and arranging meetings like that". Communication embodies the primary way in which individuals engage in extra-marital, or infidelity affairs [22], with studies reporting how SMS plays a role in starting romantic relationships [3, 23]. 
These situations put the spotlight, on the gap that exists between expectations of secrecy, which could be expected from a mobile phone, particularly if used as a personal device, and the harsh reality of the fragility of that secrecy once it is violated and exposed. The persistent nature of the data in the mobile, whether SMS, call logs, or others, accumulates as a kind of lifelog, with a value and fragility, of which we are not always aware. A study in the Philippines reported cases of infidelity, where similar fragilities are reported [3].

These types of observations show how personal communication, and even the more secret and private type of personal communication, involves social elements. Receiving and storing an SMS in this context, is not just a social situation involving the person who was the intended recipient of that message, but by looking at eavesdropping, it becomes a social situation with the eavesdropper as well. We draw on social translucence to consider this less explored facet of sociality in mobiles. In terms of visibility, the act of eavesdropping may be conducted in a way which would make it impossible for the "victim" to see, such as in the case of Lisa's father. Unless she had caught him red-handed, in the eventuality that he wouldn't have found any sensitive material in her phone, his actions would have gone unnoticed. The SMS however is a perfectly visible and shareable [2] bit of social information. What happens is that the owner of the message can be easily deprived of any awareness of the eavesdropping, while the eavesdropper may easily remain unaccountable for his or her actions.

\section{$5 \quad$ Designing for Awareness, Transience and Temporality}

At this stage we would like to acknowledge the legitimate tensions that occur around secrecy regarding personal information on the mobile, in Rah, as well as in most other places. Issues of privacy, or in this case, a very specific situation of secrecy, eavesdropping, social/cultural norms and parental/community control, are of concern to most societies where the mobile made its way. In this work, we will stay away from the grand issues that are debated in much finer detail and greater complexity in anthropological, sociological and privacy studies, among others. Suffice it to say that we are not arguing for a disenfranchising of the parent's role in education, and some level of control of their children's education, as avoiding extreme misconduct, for instance, is essential to preserve the child's need for agency and autonomy, required for a healthy development, as documented in psychological as well as HCI literature $[24,25]$. Our aim here is rather to elicit interesting domains to explore in design.

We reflect on these episodes and discuss three directions, which we find relevant for enriching the current state of interaction with mobile devices: spatial awareness, transience and temporality.

\subsection{Spatial Awareness}

When users communicate with mobile phones, they inhabit several places during the same clockwise time: the physical space and the conversational space, and are able to 
shift between them, almost as if occupying both spaces at the same time [26]. However, we saw how that flow was disrupted in Jorege's case. During his phone conversation, he tried to position his body in places with better network coverage. He also raised his voice, as this is an action that makes sense in the physical world whenever one has difficulties making oneself heard. The lack of coverage was a disrupting factor in the conversational space that he was orienting to as part of his mobile phone call. As he did this, however, he was also moving in a physical space, occupied by others. His body movement forced him to enter public areas where others might overhear part of his conversation. The inability to master the invisible coverage space and smoothly occupy all these spaces simultaneously could help explain why some wanted to drop their mobile phones and go back to using the landline, which is located in a very specific physical place.

With some notable exceptions [2], the interface of one mobile phone is the mobile phone is typically used and designed for personal use. However, the mobile phone is but one piece of the infrastructure that enables communication. When looking at the act of mobile phone mediated communication through social translucence, we can see social dynamics in the physical space that would benefit from the properties of visibility, awareness and accountability. Some authors have commented on the impact of mobile communication in institutions, their role in condensing or otherwise restructuring concepts of time and space, and how they have changed global markets or mediated experiences of remote places [27-29]. Our focus is rather on the ways that mobile communications shape individual actions. Mobile phones enable people to take part in two places at once, the physical space, where the body is located physically, is sometimes set aside in favor of the conversational space where communication occurs: "People talking on mobile phones seem wholly or partially unaware of their surroundings" [30], in a state of "absent presence" [21]. Due to this, there might be sometimes a 'friction between mobile users and co-present others' [31]. This friction has been widely noted in a number of cross-cultural studies [26, 32, 33 ], where authors explain how mobile phones temporarily disrupt public spaces for both users and bystanders. They also describe the different strategies that people use to create their own private spaces, through body orientations, refraining to talk about certain issues, or negotiation of contactability [33]. These studies highlight the complex relationships between physical space and the collective and social practices of the people who occupy it. Because of this, we argue for a contextual awareness, one that brings elements of the physical world into mobile phones (i.e. mixed reality [34]). Early work on interweaving of physical and virtual spaces has tried to design for awareness of the physical, using it as a resource in the interaction [35, 36].

More interestingly, mobile phone networks occupy a space that reaches beyond the personal device. Yet most of its components such as the network cell towers and the electromagnetic field they create remain invisible. The landline, on the other hand - at least the end terminals where communication takes place - has a known location, and is exposed, which makes the user and the possible observers visible. The network coverage space is essential to characterize the mobile phone conversational space because, if nothing else, it delimits it. Network coverage can be explicitly manipulated as in the case of deploying cell signal dampeners in public places, such 
as churches and libraries [29]. This is an example of how a social norm can be enforced through technology. The example we have observed in Rah, however, shows us a different side: the network coverage was limited due to the landscape of the archipelago and the reduced number of cell towers. Rather than enforcing a social norm, the limited coverage required people to navigate blindly, trying to find a place with better reception, especially as few of such well-known places were invariably already occupied. In Rah, the notion of "seamlessness" in communication breaks down in a very visible way. It is also apparent that the existing mobile phones were unable to provide help in defining boundaries and socially acceptable intersections of these different spaces. This indicates opportunities for designs that expose the seams of the technology - in this case the network coverage space - that mobile telephony rests on [37].

\subsection{Designing for Transience}

One of the aspects that struck us in the encounters described, was the persistent nature of the messaging communication, the call log, the SMS inbox and so on. These ultimately served as evidence against the youngsters. Of course this is a simplification of the complex social norms at stake here, not less significantly the myriad of perspectives on sexuality, infidelity and forbidden love of different sorts [22]. However, what inspired us was the mismatch between the amount of information stored in mobile devices, its rigid structuring and modes of visualization, with the everyday experiences and memories of people. To frame it within the concept of social translucence, in that particular social situation, the information of the phone may be openly exposed to whoever happens to get hold of that phone (visible). Awareness may be a challenge, in this case, given the often-long time ranges involved, and amount of information stored, making it hard for one to immediately grasp all the implications of disclosure. Finally, there is, in general no accountability, as visualization of that data by a third party is not registered in general (an exception would be in case someone is caught red-handed or would leave the phone in a different state than the user expected it to be, by leaving the messages open for instance). We will now discuss how these aspects can be harnessed, not to address directly the complex issues of infidelity and privacy, which require more than a technological intervention to be addressed, but rather how we can enrich our current HCI practice using these insights.

The overwhelming amount of digital information that we accumulate is not a new concern, with studies on email overload dating from nearly two decades ago [38]. Today, one could look back at years of email or SMS messaging history and get a very concrete outline and detailed information on different situations. At the same time, the "owner" of that communication history may only remember very fragmented bits of that history, and sometimes none at all. This property of digital information, which allows it to be stored in its intact, original form, is undoubtedly one of its most desirable properties. With memory space becoming cheaper and, in particular for SMS, the information occupying a relatively reduced amount, it may be tempting to store information on indefinitely [39]. What we can observe, on a 
fundamental level is that there are obvious differences between human memory and digital device memory [40]. This mismatch provides us with opportunities for rethinking how to design those systems with inspiration from both angles, particularly in regards to specifically designing, not only for persistence, but also for transience.

Though it has been argued that our digital possessions, like our physical possessions, help shape who we are, and how we present ourselves to others [41, 42], there are plenty of valid reasons for disposing of some those possessions. For instance, during romantic breakups [43]. Storage capacity, though as mentioned before seems less of a concern today, could still be an issue, with some modern Android phones discarding, by default, older messages, once the default cap of 200 is reached. This rather arbitrary way of deciding between persistence and transience is one which could be replaced, or complemented, with more meaningful ways that take into account other facets of those bits of communication to determine transience/persistence. We argue that there are opportunities to rethink this aspect, in relation to HCI in general, not only to address the specific issues around privacy, but rather to enrich our everyday interaction by, for instance helping us make immediate sense of our digital possessions, such as SMS messages [38, 44]. Given that, like physical possessions, not all digital possessions embody the same meaning or importance to their owners [45], there are two elements which we would like to explore, and see more explored in designing personal communication systems such as mobile phones. One is to look at how often those possessions (or SMS, in the particular case presented in this paper) are accessed, or looked at. This expression of the past activity in the present visualizations and representations is already existing in how systems such as Google, prioritize their search results. Another possible, albeit potentially more complex, approach would be to mine the data for meaning. By doing this in simple ways for instance, one could differentiate between long messages charged with emotional terms, for instance, from a shopping list or a mundane communication bit such as "call you right back!" Both of these are rather simple examples of domains we hope to see further explored in HCI.

\subsection{Temporality}

The previous discussion on transience invites us to think about visibility, awareness and accountability, in the context of privacy, by suggesting the direction of increased personalization and meaning of persistent data in personal communication systems. We would like now to extend that discussion to the broader concept of temporality. In particular, we consider the often-similar way in which information is presented in digital devices, where timestamps are usually used as the main structuring scaffold, whether for logs, display of messages and other interactions within digital technologies. These ways of structuring interaction are highly impersonal and universal. These universal modes of structuring are part of what results in such an open visibility, by making all the data comprehensible, while not drawing on the concepts of awareness and accountability.

Time and space are inseparable, synoptic concepts that constitute the fabrics of our perception $[46,47]$. According to Merleau-Ponty, it makes no sense to talk about one 
without the other [46]. Time is generated by movement, or changes in space and inversely; space exists and changes with time. This phenomenological account of time is different than the clockwise account of time, which is most prevalent in current mobile systems. The latter is intended to be independent from our perception and activity, it is the time measured by clocks and calendars and the one we mostly use to communicate and understand other people. The universal synchronization of clock time has its roots in managing railroad traffic, perhaps one situation in which it would make immediate sense.

At times it seems as if we draw on these past constructions of time, and do not question them in the context of the designs that will be built into. As design guru John Chris Jones puts it: "The time dimension, if we may call it that, is left to take care of itself' [48]. In the following, we discuss a few ways that time can be used as a resource in the design process.

\subsection{Time as a Resource in Design}

The second example from our fieldwork shows how a series of communication exchanges between two lovers, happening in a private space over a long period of time, can be disrupted. One is able to gaze into the past and observe all the conversation since the moment of its inception, as if time had collapsed. Although being personal in this context, the mobile phone has no mechanisms for protecting the privacy of the space where the conversation existed. The way the mobile phone stores the conversation, linearly, makes it easily readable by anyone. Mobile phones, in their design, tend to adopt the linearity of clocks and calendars and represent content based on a concept of clockwise time, which unlike phenomenological embodied time is space and context independent. Harper et al. draw on a similar distinction by Bergson, on temps and durée. The former more connected with the linear, objective, clock time, and the latter, reflecting a more experiential aspect [49]. As seen in studies on the Facebook timeline, linear modes of representing time can also cause awkwardness on an experiential level, for instance when photos are posted a long time after the event they refer to [49].

It is precisely on these experiential aspects we would like to draw on for design. We can find inspiration in already known modes of experiential time, relevant to our everyday experiences, such as cyclic modes of experiencing time, day/night cycles, yearly cycles and circadian rhythms, to name a few. In HCI work has been done, for instance on how to design for reflection on personal experience [50, 51]. The Affective Health system [51], where biodata is represented in a spiral, in an analogy to cyclic modes of representing time and drawing on memory recall and reflection on past events, is an example of attempts to make what is now digital data into representations which are more meaningful to users. The scheduling system named Kairoscope, also builds on this experiential mode of time to build a scheduling system which only assigns specific times to nearby events and uses a pie-chart-like interface to represent one's scheduled events [52].

The focus of the works mentioned is not specifically aimed at addressing issues of privacy and secrecy. However, creating and exploring these personal representations 
around time, has been thought of as designing for empowerment [53], rendering representations which are directly meaningful, only to the "owner" of the data. Privacy comes as a side effect of thinking about designing more personalized experiences of time. In future work we will explore how to create representations around SMS messages, which are not represented around a linear representation of the time at which the messages were received, but rather on other aspects, such as "time spent" looking at each message, and how often they are looked at, the last time they were accessed and so on. It is these directions which we find interesting to explore in HCI, since they can create representations which connect better to the users' experience and memory, as has been discussed in HCI [54].

\subsection{Beyond Time}

Extending on the previous discussion, one could imagine dropping time in design altogether. It seems like, in many cases, time is more an inherited attribute, which receives no attention in organizing data and representations in several of these systems. If not properly justified, one could wonder "why include time altogether?" Rather, one can look at more meaningful ways to visualize and organize the same information. Perhaps the frequency of looking at a certain message, briefly discussed above, and altering the ways in which messages are visualized for instance, could be a simple example of how we can think about logs without necessarily designing around clock time, whilst providing potentially more value and meaning to the user.

Worth to notice is that also in this case, one would be implicitly adding elements of accountability. That is, if someone were to look on another person's messages and that activity would be reflected on posterior visualizations of those same messages (as is the case with organizing messages around the frequency of visualization), then the element of awareness would be present, since by the mere act of eavesdropping would be posteriorly visible to the owner of the mobile, in the case of the SMS inbox. The eavesdropper, if knowledgeable on the workings of the system, would also know that their activity would be perceived later on by the owner of the mobile (who made the owner aware of this activity), thus adding an element of accountability. That action then becomes formed by the decision of whether the potential gains in doing so are higher than the potential dissatisfaction from the other party. Again, we are by no means suggesting that this is a good solution, to address the situation exemplified by the case in Rah. One could in fact speculate that it probably would not have changed the course of events, since the community would have confronted the youngsters with the incident in question once possessing that knowledge. However, one may wonder whether the person looking through the phone's messages would have avoided it so with fear of not finding anything relevant and be subjected to the potential anger of the other party whose privacy was just violated.

\section{Towards an Understanding of Digital Patina}

In this paper, we have dealt with issues of spatial awareness, transience and temporality. We have seen how these can be used as a way of thinking about mobile 
interaction design in a generative way. This discussion is not a silver bullet in addressing these issues; in fact they are not intended to be solutions at all, since we do not define those encounters as "problems" to be solved. Rather, they illustrate interesting opportunities for research in HCI and thinking about design for mobile devices. As a final remark we would like to discuss some of the potential contributions that drawing on temporality and transience can contribute to HCI and digital interaction design, specifically, the notion of digital patina.

Patina is a term referring to decay of physical artifacts, which has been known to add charm, and sometimes increased attachment or cherish for those artifacts [44, 55]. In interaction design we have seen inspiration from this, particularly in the form of bringing aesthetic, often visual, elements from real world materials, often thought of as developing patina, such as metals or leather, into the designing of visual elements for mobiles or computers at large. Some have referred to this type of inspiration as digital patina [44], since it is about bringing the elements of real world patina into the design of digital artifacts. However, we argue that there could be something much more specific to digital patina, than this skeuomorphic take on digital patina. Perhaps the temptation of adopting this approach is to draw on analogies, or metaphors, from the real world, which may remind us of different artifacts, and thus potentially evoke certain emotions [44], such as a leathery casing of an old agenda. However, as new generations, or other cultural contexts have not been exposed to those artifacts, these appropriated forms of patina may not maintain the same relevance.

Explorations around temporality and transience, for instance, and particularly forms of visualizing those dimensions in digital systems, may offer some insights into this domain. If we rethink simple aspects such as how logs and lists of messages are organized, how messages are kept and deleted, we may start getting particular forms of treating digital information which may "age" with the user and their interaction. Playing with the ageing of these structures, as opposed to perfectly conserved linear representations around universal, clock-based, timestamps, might be one way to being seriously considering what patina means for digital information. The unlimited ability to perfectly replicate data, a characteristic pertaining to digital data, makes the exploration of patina, and more generally of digital data, a most exciting direction to pursue in HCI research.

\section{References}

1. Arminen, I., Weilenmann, A.: Mobile presence and intimacy-Reshaping social actions in mobile contextual configuration. Journal of Pragmatics 41, 1905-1923 (2009)

2. Weilenmann, A., Larsson, C.: Local Use and Sharing of Mobile Phones. In: Brown, B., Green, N., Harper, R. (eds.) Wireless World: Social and Interactional Aspects of the Mobile Age, pp. 99-115. Springer (2001)

3. Ellwood-Clayton, B.: All we need is love-and a mobile phone: Texting in the Philippines. In: The International Conference on Cultural Space and the Public Sphere in Asia, Seoul, Korea (2006)

4. Ito, M., Okabe, D.: Intimate connections: Contextualizing Japanese youth and mobile messaging. In: Harper, R., Palen, L., Taylor, A. (eds.) Inside the Text Social Perspectives on SMS in the Mobile Age, pp. 127-145. Springer (2005) 
5. Horst, H.A.: The blessings and burdens of communication: cell phones in Jamaican transnational social fields. Global Networks 6, 143-159 (2006)

6. Hijazi-Omari, H., Ribak, R.: Playing with fire: On the domestication of the mobile phone among Palestinian teenage girls in Israel. Information Communication Society 11, 149-166 (2008)

7. Ito, M.: Mobile Phones, Japanese Youth, and the Re-Placement of Social Contact. In: Ling, R., Pedersen, P. (eds.) Mobile Communications Renegotiation of the Social Sphere, pp. 1-15. Springer (2001)

8. Ling, R.S.: The mobile connection: the cell phone's impact on society. Morgan Kaufmann (2004)

9. Erickson, T., Kellogg, W.A.: Social translucence: an approach to designing systems that support social processes. ACM Trans. Comput.-Hum. Interact. 7, 59-83 (2000)

10. Ferreira, P., Höök, K.: Bodily orientations around mobiles. In: Proceedings of the 2011 Annual Conference on Human Factors in Computing Systems, CHI 2011, p. 277. ACM Press, New York (2011)

11. Ferreira, P., Höök, K.: Appreciating plei-plei around mobiles. In: Proceedings of the 2012 ACM Annual Conference on Human Factors in Computing Systems, CHI 2012, p. 2015. ACM Press, New York (2012)

12. 2009 National Census of Population and Housing, Port Vila, Vanuatu (2009)

13. Crabtree, A., Rodden, T., Tolmie, P., Button, G.: Ethnography considered harmful. In: Proceedings of the 27th International Conference on Human Factors in Computing Systems, CHI 2009. Segunda Ed (2009)

14. Dourish, P.: Implications for design. Presented at the (2006)

15. Geertz, C.: The Interpretation of Cultures: Selected Essays. Basic Books (1973)

16. Taylor, A.S., Harper, R.: The Gift of Gab? A Design Oriented Sociology of Young People's Use of Mobiles. Computer Supported Cooperative Work 12, 267-296 (2003)

17. Licoppe, C., Heurtin, J.-P.: The cellular phone as a tool for managing risk and trust in social bonds: re-locating mobile phone users and re-synchronizing unexpected contexts in cellular phone interactions. In: Katz, J., Aakhus, M. (eds.) Perpetual Contact: Mobile Communication, Private Talk, Public Performance, pp. 94-109. Cambridge University Press, Cambridge (2002)

18. Licoppe, C.: "Connected" presence: the emergence of a new repertoire for managing social relationships in a changing communication technoscape. Environment and Planning D: Society and Space 22, 135-156 (2004)

19. Green, N.: Who's watching whom? Monitoring and accountability in mobile relations. In: Brown, B., Green, N., Harper, R. (eds.) WirelessWorld: Social and Interactional Aspects of the Mobile Age. Springer (2001)

20. Monk, A., Carroll, J., Parker, S., Blythe, M.: Why are mobile phones annoying? Behaviour \& Information Technology 23, 33-41 (2004)

21. Gergen, K.: The challenge of the absent presence. In: Katz, J.E., Aakhus, M.A. (eds.) Perpetual Contact Mobile Communication Private Talk Public Performance, pp. 227-241. Cambridge University Press (2002)

22. Mattingly, B.A., Clark, E.M., Weidler, D.J., Bullock, M., Hackathorn, J., Blankmeyer, K.: Sociosexual Orientation, Commitment, and Infidelity: A Mediation Analysis. The Journal of Social Psychology 151, 222-226 (2011)

23. Byrne, R., Findlay, B.: Preference for SMS versus Telephone Calls in Initiating Romantic Relationships. Society 2, 48-61 (2004)

24. Maccoby, E.: The role of parents in the socialization of children: An historical overview. Developmental Psychology 28, 1006-1017 (1992) 
25. Yardi, S., Bruckman, A.: Social and technical challenges in parenting teens' social media use. In: Proceedings of the 2011 Annual Conference on Human Factors in Computing Systems, CHI 2011, p. 3237. ACM Press, New York (2011)

26. Höflich, J.R., Hartmann, M.: Mobile communication in everyday life: ethnographic views, observations and reflections. Presented at the (2006)

27. Castells, M.: The Rise of the Network Society, vol. I. Wiley-Blackwell (2010)

28. Tsatsou, P.: Reconceptualising "Time" and "Space" in the Era of Electronic Media and Communications. Journal of Media and Communication 1, 11-32 (2009)

29. Dourish, P., Bell, G.: The infrastructure of experience and the experience of infrastructure: meaning and structure in everyday encounters with space. Environment and Planning B Planning and Design 34, 414-430 (2007)

30. Persson, A.: Intimacy Among Strangers: On mobile telephone calls in public places. Journal of Mundane Behavior (2001)

31. Cooper, G.: The mutable mobile: social theory in the wireless world. Springer Computer Supported Cooperated Work Series, pp. 19-31 (2001)

32. Ling, R.: One can talk about common manners!': the use of mobile telephones in in appropriate situations. Telektronikk 94, 65-78 (1998)

33. Haddon, L.: The Social Consequences of Mobile Telephony: Framing Questions. Sosiale Konsekvenser av Mobiltelefoni. Telenor, Oslo (2000)

34. Milgram, P., Kishino, F.: A Taxonomy of Mixed Reality Visual Displays. IEICE Transactions on Information Systems E77-D (1994)

35. Benford, S., Greenhalgh, C., Reynard, G., Brown, C., Koleva, B.: Understanding and constructing shared spaces with mixed-reality boundaries. ACM Transactions on Computer-Human Interaction 5, 185-223 (1998)

36. Dix, A., Rodden, T., Davies, N., Friday, A., Palfreyman, K.: Exploiting Space and Location as a Design Framework for Interactive Mobile Systems. ACM Transactions on Computer-Human Interaction 7, 285-321 (2000)

37. Chalmers, M., MacColl, I.: Seamful and seamless design in ubiquitous computing. Presented at the (2003)

38. Whittaker, S., Sidner, C.: Email overload: exploring personal information management of email. In: Kiesler, S. (ed.) Proceedings of the SIGCHI Conference on Human Factors in Computing Systems Common Ground, pp. 276-283. ACM (1996)

39. Bell, G., Gemmell, J.: Total Recall: How the E-Memory Revolution Will Change Everything. Dutton Adult (2009)

40. Van House, N., Churchill, E.F.: Technologies of memory: Key issues and critical perspectives. Memory Studies 1, 295-310 (2008)

41. Kirk, D., Sellen, A.: On Human Remains: Excavating the Home Archive. Microsoft Research Cambridge UK. MRS-TR-2008-8 (2008)

42. Odom, W., Zimmerman, J., Forlizzi, J.: Teenagers and their virtual possessions. In: Proceedings of the 2011 Annual Conference on Human Factors in Computing Systems, CHI 2011, p. 1491. ACM Press, New York (2011)

43. Sas, C., Whittaker, S.: Design for Forgetting: Disposing of Digital Possessions Afer a Breakup. In: Proceedings of the Forthcoming SIGCHI Conference on Human Factors in Computing Systems. ACM, New York (2013)

44. Odom, W., Banks, R., Kirk, D., Harper, R., Lindley, S., Sellen, A.: Technology heirlooms?: considerations for passing down and inheriting digital materials. In: Proceedings of the 2012 ACM Annual Conference on Human Factors in Computing Systems, CHI 2012, pp. 337-346. ACM (2012) 
45. Odom, W., Pierce, J., Stolterman, E., Blevis, E.: Understanding why we preserve some things and discard others in the context of interaction design. In: Proceedings of the 27th International Conference on Human Factors in Computing Systems, CHI 2009, p. 1053. ACM Press, New York (2009)

46. Lanigan, R.: Speaking and semiology: Maurice Merleau-Ponty's phenomenological theory of existential communication. Walter de Gruyter (1991)

47. Lash, S.: Another modernity, a different rationality. Wiley-Blackwell (1999)

48. Jones, J.C.: Design Methods. Wiley (1992)

49. Harper, R., Whitworth, E., Page, R.: Identity, Time and Durée on Facebook. Selected Papers of Internet Research (2012)

50. Lindley, S.E., Glancy, M., Harper, R., Randall, D., Smyth, N.: Oh and how things just don't change, the more things stay the same": Reflections on SenseCam images 18 months after capture. International Journal of Human-Computer Studies 69, 311-323 (2011)

51. Sanches, P., Höök, K., Vaara, E., Weymann, C., Bylund, M., Ferreira, P., Peira, N., Sjölinder, M.: Mind the body!: designing a mobile stress management application encouraging personal reflection. In: Proceedings of the 8th ACM Conference on Designing Interactive Systems, pp. 47-56 (2010)

52. Martin, R., Holtzman, H.: Kairoscope: managing time perception and scheduling through social event coordination. In: Proceedings of the SIGCHI Conference on Human Factors in Computing Systems, pp. 1969-1978. ACM, New York (2011)

53. Höök, K., Ståhl, A.: Interactional empowerment. In: Proceedings of the Twenty- ..., pp. 647-656. ACM, New York (2008)

54. Harper, R., Randall, D., Smyth, N., Evans, C., Heledd, L., Moore, R.: The Past is a Different Place: They Do Things Differently There. Sociology The Journal Of The British Sociological Association, 271-280 (2008)

55. DeSilvey, C.: Observed Decay: Telling Stories with Mutable Things. Journal of Material Culture 11, 318-338 (2006) 